\title{
$\int_{1}^{P} \mid$
}

POLYTECHNIC

\section{Developing Unmanned Aerial Systems Skills Through a Creative Project}

\section{Student researchers: Jesse Giampaolo and James Jeffery Hines, Juniors}

Use of unmanned aerial systems (UAS), commonly known as drones, in both civilian and military applications has risen significantly in the past decade. The ability to remotely conduct hazardous, physically taxing, and otherwise expensive tasks makes UAS an invaluable tool. In the coming years, the UAS industry is projected to experience significant growth, meaning an increase in career opportunities. As this demand for UAS professionals rises, universities are beginning to offer specialized programs in UAS. At the same time, STEM-focused (science, technology, engineering, and mathematics) industries are looking for well-rounded, creative graduates to solve the next generation of problems. This research examines how creative freedom can be used as a motivator for learning and improving technical skills required to work in the UAS industry.
Students were given the semester to collect footage and create a short, two-minute video on a topic of their choice. The main restrictions included the length of the video and legality of the flight. Data was collected via a 20 -question, 7-point Likert scale survey distributed at the beginning and end of the semester. The survey recorded a subject's knowledge as well as comfort in areas of operational proficiency for a UAS operator. The sample size before and after the project were $\mathrm{n}=19$ and $\mathrm{n}=13$, respectively. The preliminary results suggest that these students improved technical skills in essential areas such as troubleshooting, flight control, and regulations. Further research will be conducted attempting to correlate freeform instruction and an increase in technical skill.

Research advisor Brian Kozak writes: "Jesse and Jeff's research focused on using a creative project to increase technical skills in an unmanned aerial systems operator. Evaluation of the project was conducted by using pre- and post-surveys, and data collected indicates a successful experiment. A follow-on study is being developed." 

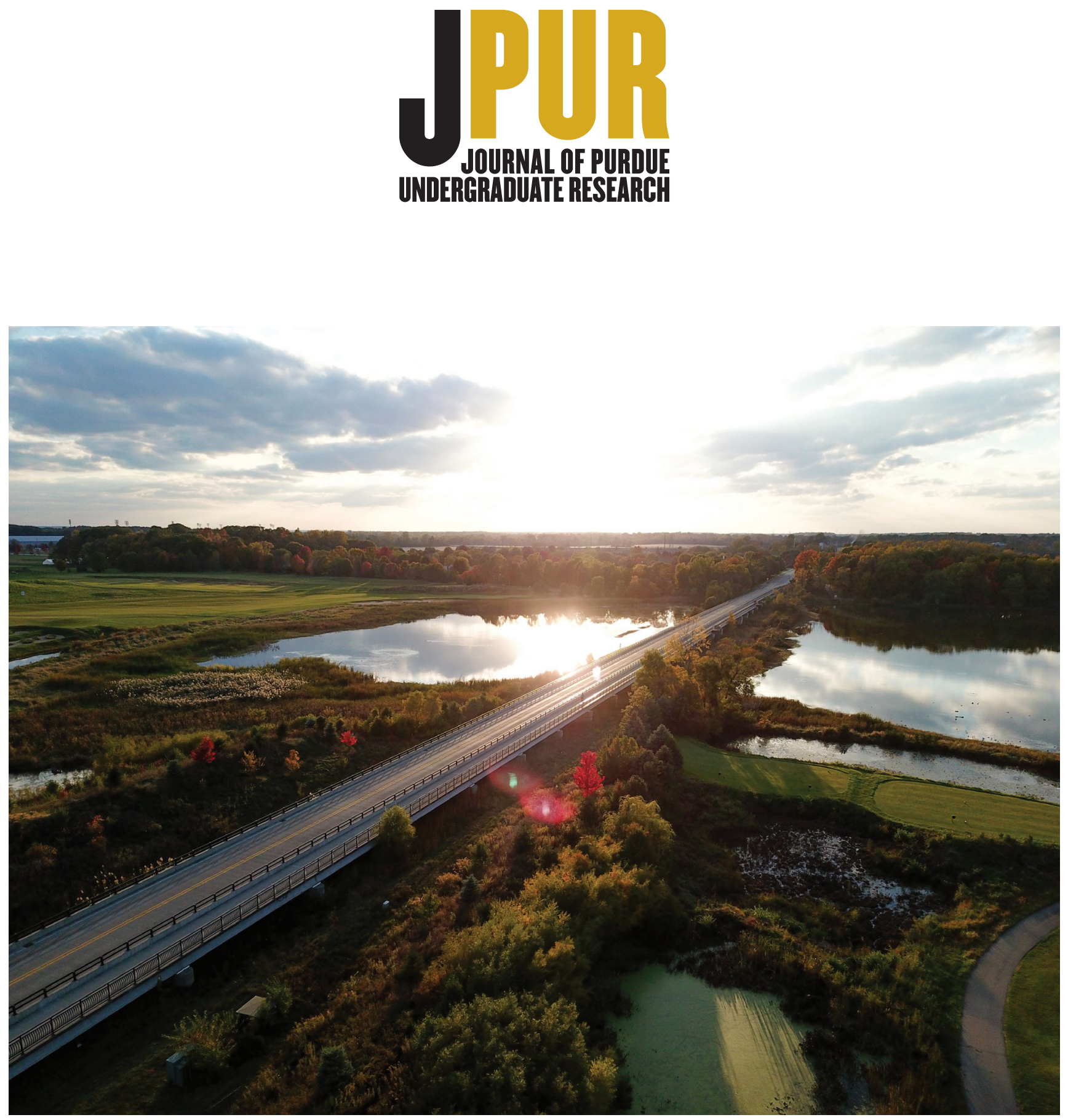

Screenshot taken from a student's creative project. Subject is the Celery Bog in West Lafayette, IN. 